\title{
Age as a Risk Factor of Relapse Occurrence in Acute Lymphoblastic Leukemia-L1 (All-L1) in Children
}

\author{
Yulianty Mochtar*, Nadirah Rasyid Ridha, Dasril Daud \\ Department of Pediatrics, Medical Faculty, Hasanuddin University, Makassar, Indonesia \\ Email address: \\ yuliantymochtardr@yahoo.com (Y. Mochtar),nadirah.bika@gmail.com (N. R. Ridha), drdasril@gmail.com (D. Daud) \\ To cite this article: \\ Yulianty Mochtar, Nadirah Rasyid Ridha, Dasril Daud. Age as a Risk Factor of Relapse Occurrence in Acute Lymphoblastic Leukemia-L1 \\ (All-L1) in Children. American Journal of Clinical and Experimental Medicine. Vol. 3, No. 3, 2015, pp. 122-127. \\ doi: 10.11648/j.ajcem.20150303.19
}

\begin{abstract}
Introduction: Relapse in children with leukemia is a phase appearing the leukemia cells after complete remission; this situation can impact the children itself, parents and also the support system. Objective: To identify the factors related of relapse incidence in children with leukemia. Methods: This study was conducted by using a retrospective cohort study design based on medical record data from Dr. Wahidin Sudirohusodo Hospital, Makassar from December 2013 until August 2014. Study samples were children of 0 month - 18 years old diagnosed of having Acute Lymphoblastic Leukemia-L1. They are treated with chemotherapy and divided into relapse and non-relapse samples. Results: From 42 relapse and non-relapse samples, there were $35.7 \%$ (15) relapse samples and $64.3 \%$ (27) non relapse samples. Bivariate analyses revealed that among 1-10 year, there were $31.4 \%$ (11) with relapse and $68.6 \%(24)$ without relapse. Among the samples aged more than 10 years old, there were $57.1 \%$ (4) samples with relapse and $42.9 \%$ (3) samples without relapse, with $p=0.225$ ( $p>0.05$ ). In terms of interval time from first diagnosis until the occurrence of relapse, the median value was 1.80 in 1-10 year-old group. In the group of $>10$ years old, the median value was 0.84 and $p=0.207(p>0.05)$. Conclusion: Age did not give any influence in the incidence of relapse in children with ALL-L1 and the interval time when the first diagnosed until relapse.
\end{abstract}

Keywords: Acute Lymphoblastic Leukemia-L1, Relapse, Age, Children

\section{Introduction}

Acute lymphoblastic leukemia (ALL) is a leukemia that found in children with $20 \%-30 \%$ of malignancy in children with a peak incidence of age 2-5 years. ${ }^{1}$ The incidence of leukemia in the United States in 2000 approximately 3600 children and the incidence are 4.1 new cases per 100.000 children aged less than 15 years. In developing countries, there are approximately $83 \%$ of ALL, $17 \%$ of acute myeloblastic leukemia (AML) and higher in white children than the dark children. In Japan at 4 per 100.000 children and each year is estimated occur in 1000 new cases. ${ }^{2}$ While in Indonesia in 1994, the incidence reached 2.5-4.0 per 100.000 children with an estimated of 2000-3200 ALL new cases each year. $^{3}$

Several studies have reported the proportion of male patients is higher than female, especially after the first age of life. The proportion becomes more dominant at the age of 615 years. The ratio of male and female was 1.15 in the ALL and close to 1 for the AML. Patient siblings with ALL have four times higher risk developing into ALL, whereas monozygotic twins have a $20 \%$ risk. $^{4,5}$ ALL is a precursor stage malignancy of lymphoid cells which according to the World Health Organization (WHO) grouped by its immunophenotype is ALL B-cells and T-cells. Environmental and genetic factors linked to the risk of ALL. However, to date certainly from ALL etiology still remains unclear. ${ }^{6}$

Several clinical and biological factors affect ALL prognoses, such as age, leukocyte count, sex, the ALL phenotype, central nervous system (CNS) infiltration, abnormal chromosomes, minimal residual disease (MRD) and the initial response to chemotherapy. For decades, these prognostic factors have been used to stratify the ALL treatment, so patients are grouped into groups of high risk and low risk. ${ }^{7}$ ALL is a neoplastic disease produced by somatic mutations in single lymphoid progenitor cells in one of the several levels of development. ALL relapse is a threat of a lifetime for ALL patients'. There is $68 \%$ in ALL children with aged 0-14 years had a 5 year survival from 1978 to 1986 , whereas in 1986 and 1992 increased to $79 \%$ and increased again by $10 \%$ in 1983 and 1985 . Although there has been an 
increase in the ALL therapy in children, the incidence of ALL relapse is the main factors contribute to morbidity and mortality in children with this disorder. In a case of 3712 children with ALL in 1883 to 1989, obtained 1144 children (84\%) experienced relapse at one place or more. Bone marrow, CNS and testicular is the most common relapse, while other places are rare to relapse is lymph nodes, eyes and bones. 8

Age mechanism affects the prognosis remains unclear yet to this day. The most likely mechanism is the difference in telomere length and telomerase activity in different age levels. In very young ALL patient, the telomere length and telomerase activity is higher. Telomerase is telomeressynthesizing reverse transcriptase which compensates for the loss of telomeres during the lymphoblast replication. A high telomerase activity indicates a proliferation of lymphoblast. In addition to the ALL children, age was also associated with the nature of lymphoblast. At older ages, lymphoblasts derived from lymphoid precursors that are relatively more potential pluri generally proliferate faster and less responsive to chemotherapy. ${ }^{10,}{ }^{11}$ By the improvement of the management and intensification therapy, some of these prognostic factors were no longer significant as predictors of ALL outcomes. At the same time, the development of laboratory methods (immunophenotype and cytogenetic) has become a new factor affecting the prognosis of leukemia classification. ${ }^{7}$

Although there has been improvement in ALL survival, children aged 1-10 years had a survival rate of two times higher to children aged less than 1 year or more than 10 years. ${ }^{12}$ Similarly of the incidence in ALL relapse, high risk of relapse was found in children aged less than 1 year or more than 10 years is greater than 1-10 years., 7 Age differences of ALL relapsed observation allegedly associated with immunophenotype and cytogenetic from ALL. In children aged $<1$ year of high early leukocyte count, rearrangement of the mixed lineage leukemia (MLL) is a poor prognostic factor associated with the success treatment. ${ }^{13}$ While, children $>10$ years with $\mathrm{T}$ cell leukemia, pseudo diploid abnormal chromosome, MLL, and Filadelpia chromosome become a poor prognostic factor for relapse. Another case in children aged 1-10 years, more favorable cytogenetic obtained such as DNA index $\geq 1.16$ (hyper diploid chromosome) and the Translocation Ets LeukemiaAcute Myeloid Leukemia-1 (TEL/AML-1) gene fusion. These factors have a role in the leukemia pathogenesis. ${ }^{7,14}$

Based on the information above, it is clear that the age affect in determining relapse in children with ALL. Therefore, it is important to know the incidence of relapse in children with certain age groups. The general objective of this study is to identify the age of patients with ALL-L1 as a risk factor of relapse occurs.

\section{Materials and Methods}

This study is an observational retrospective cohort study to determine the relationship of age in ALL-L1 patients with the incidence of relapse, and to determine the risk of relapse incidence according to the age in patients with ALL-L1. This study was conducted in inpatient of Dr. Wahidin Sudirohusodo hospital Makassar using medical records of patients with ALL- L1 in hemato-oncology division of Department of Child Health since December 2013 to August 2014.

We obtained the approval by the Ethics and Industry Research Committee of the hospital and Medical Faculty of Hasanuddin University and written informed consent from the patients' parents or legal guardian following full and detail explanation regarding the study's protocol before we begin the study. Samples are affordable throughout the population who met the inclusion and exclusion criteria. The inclusion criteria are all patients ALL-L1 listed in hematooncology division of the Department of Pediatrics Dr Wahidin Sudirohusodo hospital, with undergoing chemotherapy since 2006 experienced a complete remission and relapse occurred, and children aged $\leq 18$ years. While the exclusion criteria are ALL type L3 and patients who did not undergo chemotherapy treatment protocol. The sampling is through medical records of patients subsequently recorded data related to study. We recording the patients registered, sex, age while therapy, body mass index, include into the standard or high risk, presence or absence of mediastinal masses, hyperleukositosis or not, presence of infiltration into the CNS and bone marrow, the relapse after complete remission induction phase and relapse following chemotherapy.

Then, the patients are divided into relapse and non relapse group based on diagnosis and chemotherapy. Sample was divided according to three age groups, such are $<1$ years, 110 years, and $>10$ years. All samples have reached complete remission. Then further analyses of data based on these risk factors with appropriate statistical methods through univariate and bivariate analyses, we compared the relapse occurrence between the three groups. Results of hypothesis testing is not significant, when $\mathrm{p}>0.05$, significant if $\mathrm{p} \leq 0.05$, and very significant if $\mathrm{p}<0.01$.

\section{Results}

Table 1 shows the study sample characteristics. Of all the 42 patients with ALL-L1 diagnosed of complete remission, it obtained 35 children 1-10 years and 7 children $>10$ years. Besides, majority of the study samples are male children, well nutrition, standard risk, and early leucocytes count $<500.000 / \mu \mathrm{L}$.

Study sample are grouped into relapse and non relapse, then the risk factors is analyzed including the sex, nutrition status (well nutrition, under/poor nutrition and obesity), risk group (high and standard risk) and the early leucocytes count $(<50.000 / \mu \mathrm{L}$ dan $>50.000 / \mu \mathrm{L})$. Table 2 shows the relationship between the incidences of age group relapse. The frequency of children aged $1-10$ years with relapse is $31.4 \%$ and $68.6 \%$ on non relapse children. Whereas the frequency of children $>10$ years with relapse is $57.1 \%$ and $42.9 \%$ on non 
relapse. Statistically, there is no significant difference between both groups with value $\mathrm{p}=0.225(\mathrm{p}>0.05)$.

Table 1. The study sample characteristics.

\begin{tabular}{|c|c|c|c|c|}
\hline \multirow{3}{*}{ Patient characteristics } & \multicolumn{3}{|c|}{ Groups n= 42} & \\
\hline & \multicolumn{2}{|c|}{$1-10$ years $n(\%)=35(83.3)$} & \multicolumn{2}{|c|}{$>10$ years $n(\%)=7(16.7)$} \\
\hline & Relapse & Non Relapse & Relapse & Non relapse \\
\hline \multicolumn{5}{|l|}{ Sex } \\
\hline Male & $5(29.4 \%)$ & $12(70.6 \%)$ & $3(60 \%)$ & $2(40 \%)$ \\
\hline Female & $6(33.3 \%)$ & $12(66.7 \%)$ & $1(50 \%)$ & $1(50 \%)$ \\
\hline \multicolumn{5}{|l|}{ Nutritional status } \\
\hline Well & $6(37.5 \%)$ & $10(62.5 \%)$ & $2(50 \%)$ & $2(50 \%)$ \\
\hline Under & $4(26.7 \%)$ & $11(73.3 \%)$ & $2(66.7 \%)$ & $1(33.3 \%)$ \\
\hline Poor & 0 & $3(100 \%)$ & 0 & 0 \\
\hline Obesity & $1(100 \%)$ & 0 & 0 & 0 \\
\hline \multicolumn{5}{|l|}{ Risk Group } \\
\hline High Risk & $6(60 \%)$ & $4(40 \%)$ & $3(60 \%)$ & $2(40 \%)$ \\
\hline Standard Risk & $5(20 \%)$ & $20(80 \%)$ & $1(50 \%)$ & $1(50 \%)$ \\
\hline \multicolumn{5}{|l|}{ Early WBC } \\
\hline$<50.000 / \mu \mathrm{L}$ & $8(26.7 \%)$ & $22(73.3 \%)$ & $2(50 \%)$ & $2(50 \%)$ \\
\hline$>50.000 / \mu \mathrm{L}$ & $3(60 \%)$ & $2(40 \%)$ & $2(66.7 \%)$ & $1(33.3 \%)$ \\
\hline
\end{tabular}

( ): percentage WBC: White blood cell

Table 2. Relationship between age group on relapse incidences.

\begin{tabular}{llll}
\hline \multirow{2}{*}{$\begin{array}{l}\text { Age group } \\
\text { (years) }\end{array}$} & \multicolumn{2}{l}{ Relapse Incidences } & \multirow{2}{*}{ Total } \\
\cline { 2 - 3 } & Relapse & Non relapse & \\
\hline $1-10$ & $11(31.4 \%)$ & $24(68.6 \%)$ & $35(100 \%)$ \\
$>10$ & $4(57.1 \%)$ & $3(42.9 \%)$ & $7(100 \%)$ \\
Total & $15(35.7 \%)$ & $27(64.3 \%)$ & $42(100 \%)$ \\
\hline
\end{tabular}

Fisher's Exact test $\mathrm{p}=0.225(\mathrm{p}>0.05)$

Table 3 shows the relationship between times interval at the early diagnosed until the relapse occurrence on the patients' age group. Times interval at the early diagnosed until the relapse occurrence on the 1-10 years age group with mean 2.13; median 1.80; deviation standard 1.57 and have a minimum-maximum $0.20-5.55$. whereas, the $>10$ years age group with mean 1.02; median; 0.84; deviation standard 0.84 and have a minimum-maximum 0.22-2.18. Statistically, there is no significant difference between both groups with value $p$ $=0.207(\mathrm{p}>0.05)$.

Table 3. Relationship between times interval at the early diagnosed until the relapse occurrence on the patients'age.

\begin{tabular}{lll}
\hline Diagnosed interval- & Age (years) & \\
\cline { 2 - 3 } Relapse & $\mathbf{1 - 1 0}$ years & $>\mathbf{1 0}$ years \\
\hline Mean & 2.13 & 1.02 \\
Standard deviation & 1.57 & 0.84 \\
Range & $0.20-5.55$ & $0.22-2.18$ \\
\hline
\end{tabular}

$\mathrm{t}$ test $=1.329 \mathrm{df}=13 \mathrm{p}=0.207(\mathrm{p}>0.05)$

Table 4 shows the relationship between times interval to the complete remission until the relapse occurrence to patients' age group. In the 1-10 years age group with mean 1.74; median 1.67; deviation standard 1.57 and have a minimum-maximum $0.03-5.38$. Whereas the $>10$ years age group with mean 0.42 ; median 0.23 ; deviation standard 0.50 and have a minimum-maximum $0.08-1.16$. Statistically, there is no significant difference between both groups with value $p$ $=0.131(\mathrm{p}>0.05)$.
Table 4. Relationship between times interval to complete remission until relapse occurrence to patients'age group.

\begin{tabular}{lll}
\hline Remission complete interval- & Age (years) \\
\cline { 2 - 3 } Relapse & $\mathbf{1 - 1 0}$ years & $>\mathbf{1 0}$ years \\
\hline Mean & 1.74 & 0.42 \\
Standard deviation & 1.57 & 0.50 \\
Range & $0.03-5.38$ & $0.08-1.16$ \\
\hline
\end{tabular}

$\mathrm{t}$ test $=1.613 \mathrm{df}=13 \mathrm{p}=0.131(\mathrm{p}>0.05)$

\section{Discussion}

In our study, the age group of 1-10 years relapse experienced is $31.4 \%$ and the non relapse is $68.6 \%$. Whereas the age of $>10$ years with relapse experienced is $57.1 \%$ and the non relapse is $42.9 \%$. Relationship of age group to relapse occurrence shows there is no significant difference with value $p=0.225(p>0.05)$. This is same with Meidiana's study in Jakarta that age has no significant difference to relapse occurrence for the ALL-L1 cases in children. ${ }^{15}$

This study found that many of patients with early leukocyte counts $<50.000 / \mu \mathrm{L}$ did not experience relapse after treatment, especially in the age group 1-10 years. This is similar with Silverman research in 2000 that children with leukocytes $>50.000 / \mu \mathrm{L}$ with age $<1$ years and $>10$ years are generally included in the category of high risk of relapse and getting intensive therapy. ${ }^{7}$ Similarly, Permono states that the number of peripheral blood leukocytes in ALL early diagnostic is very important factor in determining the prognosis. ${ }^{16}$ The high count of leukocyte is one of the biggest cause of the high relapse.

The relationships of times interval to the early diagnosed until the relapse occurrence is observed of ages, which the ALL-L1 patients relapse interval median of $1-10$ years is 1.8 years and the $>10$ years is 0.84 years. Relationships of times interval to the early diagnosed until the relapse occurrence of the ages did not has a meaningful difference with value $p=$ 
0.207 ( $p>0.05$ ). Relationships of times interval to complete remission until the relapse occurrence to age group in this case obtained that the relapse interval median counts from the complete remission of ALL-L1 patients in group 1-10 years is 1.67 years and in group $>10$ years is 0.23 years. Observation on relationships of times interval on complete remission until the relapse occurrence did not has a significant difference with value $p=0.131(p>0.05)$. This result did not appropriated according to Plasschaert and Pui research that the resistance to chemotherapy has relation with age, the factors cause children age $<1$ years and $>10$ years are less profitable is the highest of T-cell ALL incidence accompanied with the lowest of well DNA index incidents, the early high leucocytes count, hypo diploid abnormal chromosome, rearrangement of the mixed lineage leukemia (MLL), and the Filadelpia chromosome that affect the successful treatment so as the relapse occurs in the early.

In this study, the incidence of relapse was found at the time undergoing chemotherapy after passing through the induction phase and there has been a spontaneous remission, and those that are found after 2 years undergoing chemotherapy. The patient experienced a complete remission has been declared because of cerebral spinal fluid examination showed normal cellularity with lymphoblast of $\leq 5 \%$. This does not guarantee that a patient who has passed the stage of chemotherapy will not relapse.

The strength of this study is using a retrospective cohort study as the first time in South Sulawesi to assess the age affect on relapse occurrence of ALL-L1 children in the biggest hospital in East Indonesia. Limitations of this study are solely using existing data from the medical record that has some drawbacks, thus the data is incomplete or not in accordance as required. We concluded that age did not affect the relapse occurrence on ALL-L1 in children. Times interval on the early diagnosed until relapse occurrence did not depend on the age group and neither the times interval on complete remission until the relapse occurrence. Study is better adding the supporting investigation, such as immunofenotype examine, cytogenetic and detection of residual disease. It is also important to give a special intention on children age $>10$ years with ALL-L1 diagnosed.

\section{References}

[1] Pui CH, Evans. Acute lymphoblastic leukemia. Eng J Med. 2004; 339: 605-15.
[2] Cancer Council. Statistics Leukemia. Updated March 2009 based on latest data (2006). 2009.

[3] Mostert, Saskia., Sitaresmi M.N., Gundy C.M., Sutaryo., Veerman A.J. Influence of socioeconomic status on childhood acute lymphoblastic leukemia treatment in Indonesia. Pediatrics. 2006; 118e:1600-1606.

[4] Silverman L.B., Sallan S.E. Acute lymphoblastic leukemia. Hematology of infancy and children. Saunder. 2003; 6: 113566.

[5] Margolin J.R., Stember C.P., Poplack D.G. Principles and practice of pediatric oncology. Philadelpia. 2002; 489-544.

[6] Rubnitz J.E., Crist W.M. Molecular genetics of childhood cancer: Implications for pathogenesis, diagnosis, and treatments. Pediatrics. 1997; 100: 101-08.

[7] Silverman L.B. Childhood acute lymphoblastic leukemia: Currently applied prognostic factors. International Society of Paediatric oncology. 2000.

[8] Beutler, Ernest, et al., 2000. Williams Hematology 6th edition. New York: McGraw-Hill Professional.

[9] Hoffman, R., Benz, E. J., Shattil, S. J., Furie, B., Cohen, H. J., Silberstein, L. E., et al. (Eds.). Hematology: basic principles and practice, 3rd edition. New York: Churchill Livingstone. 2000 .

[10] Plasschaert L.S., Kamps W.A., Velengga E. Prognosis in childhood acute lymphoblastic leukemia: A question of maturation. Cancer Treat Rev. 2004; 30: 37-51.

[11] Niemeyer C.M., Sallan S.E. Acute lymphoblastic leukemia. In: Nathan DG, Orkin SH. Hematology of Childhood and Infancy. Philadelphia. Saunders. 1998; 5

[12] Widiaskara dkk., Outcomes phase induction treatment of acute lymphoblastic leukemia in children at Dr. Soetomo hospital. Sari Pediatri. 2010; 12 (2).

[13] Mulatsih S., Silvia M. Acute lymphoblastic leukemia in children age under one year old. Sari Pediatri. 2009; 3 (4): 102-07.

[14] Pui C.H., Boyett J.M., Rivera G.K. Long term results of total therapy studies 11, 12 and 13 A for childhood acute lymphoblastic leukemia at St Jude Children's Research Hospital. Leukemia. 2000; 14: 2286-294.

[15] Meidiana B. Factor analyses of genesis relapse in children with leukemia. Jakarta: RS Cipto Mangunkusomo. 2012.

[16] Permono B., Sutaryo., Ugrasena I.D.G., Windiastuti E. Acute leukemia in Hematology-Oncology of Child Textbook. Jakarta: Publisher Agency of Indonesian Pediatric Association. 2006; 2. 